\title{
O GÊNERO OMBUDSMAN: DA ORGANIZAÇÃO RETÓRICA AO SISTEMA DE ATIVIDADES*
}

\author{
THE OMBUDSMAN GENRE: FROM THE RHETORICAL ORGANIZATION TO THE \\ ACTIVITY SYSTEM
}

Andréa Regina Sarmento
Mestranda do Programa de Pós-graduação em Linguística - UFSC - CAPES
Nívea Rohling da Silva
Doutoranda do Programa de Pós-graduação em Linguística - UFC - CAPES

\section{Resumo}

Este artigo apresenta uma análise do gênero ombudsman na perspectiva teórica da sócio-retórica proposta por Swales (1990) e Bazerman (2006a[2004]), 2006b; 2007). Os dados de pesquisa são compostos de quinze exemplares do gênero, publicados no jornalismo on-line no período de 07 de dezembro de 2008 a 04 de janeiro de 2009. A análise mostrou que o jornalista que ocupa a função de Ombudsman constitui-se como parte integrante de um complexo sistema de atividades no campo do jornalismo e tem uma prerrogativa de autorregulação do próprio fazer jornalístico. Nesse sistema de atividades, observou-se que há a mobilização de um conjunto de enunciados de gêneros distintos para que a crítica ao jornal - vista neste trabalho como ação de linguagem - materialize-se por meio do gênero ombudsman.

Palavras-chave: Ombudsman. Organização retórica. Sistema de atividades de gêneros. Gênero ombudsman.

\begin{abstract}
This article presents an analysis of the ombudsman genre, using the theory proposed by Swales (1990) and Bazerman (2006a [2004]), 2006b; 2007). The data for this research was composed of 15 texts of the genre, published in three different online newspapers from December $7^{\text {th }}, 2008$ to January $4^{\text {th }}, 2009$. The analysis showed that the journalist called Ombudsman is part of a complex activity system in the journalism field and has a prerogative of self-regulation from the journalism work itself. It was possible to observe, in this activity system, the mobilization of a set of utterances of distinct genres in order to make the criticism to the online newspaper considered here as a speech act - happen through the ombudsman genre.
\end{abstract}

Keywords: Ombudsman. Rhetorical organization. Genre activity system. Ombudsman genre.

\section{INTRODUÇÃO}

A figura do Ombudsman ${ }^{1}$ surge oficialmente em 1809, na Suécia, com um status de ministro e a função de fiscalizar o poder público e ouvir as queixas que os cidadãos

\footnotetext{
* Como explicado na introdução deste número da revista, esta pesquisa foi desenvolvida na disciplina: LIN 4002-078 Seminário de Especialidade: Teorias de Gêneros do Discurso, ministrada pela Profa. Dra. Rosângela Hammes Rodrigues, no Programa de Pós-Graduação em Linguística (UFSC).

${ }^{1}$ No decorrer deste texto, utilizamos o termo ombudsman em iniciais minúsculas e de forma destacada para nos referirmos ao nosso objeto de estudo - o gênero. Porém, em alguns momentos, utilizamos Ombudsman - inicial maiúscula - para fazer menção ao jornalista que ocupa essa função na empresa jornalística.
} 
tinham contra os órgãos governamentais. Posteriormente, a função foi adotada em outros países, principalmente os escandinavos, com enfoque nas críticas relativas à discriminação étnica, críticas de consumidores etc. (MENDES, 1999). Desse modo, inicialmente, a função de Ombudsman não está ligada à atuação na imprensa, mas à esfera pública (no sentido de serviços públicos) de forma geral. Nesse cenário, o Ombudsman é tido como um ouvidor que assume a responsabilidade de manifestar as críticas feitas por usuários de serviços de determinada organização da esfera pública.

$\mathrm{Na}$ esfera do jornalismo diário, Minuzzi (2006, p. 1) considera que “[...] o ombudsman age basicamente através da escuta de leitores, na maioria das vezes insatisfeitos, ou com alguma queixa a apresentar, a partir da condição de consumidores de um produto informativo".

$\mathrm{Na}$ ação de "ouvir" os leitores e escrever uma coluna semanal que manifeste as críticas dos leitores, o Ombudsman configura-se como um importante elemento no sistema de autorregulação da imprensa. Nesse contexto discursivo, ocorre a produção e a circulação do gênero ombudsman - publicado na impressa diária. Em nosso entendimento, a constituição desse gênero está intimamente ligada à noção de gênero como ação social que cumpre funções específicas, envolvendo agentes específicos que desempenham seus papéis no sistema de atividade, conforme proposto por Bazerman (2006a), Miller (1984) e Swales (1990). Ou seja, a constituição do gênero ombudsman está ancorada na prática social dos interactantes, no universo do trabalho do jornalista que cumpre uma função específica: manifestar uma crítica à empresa jornalística com o objetivo de ser um autorregulador dessa mídia. Todas essas especificações, a nosso ver, tornam esse gênero um instigante objeto de investigação.

Assim, com vistas a ampliar os estudos de gênero, neste artigo, tematizamos a análise do gênero ombudsman, da esfera jornalística, mais precisamente do jornalismo diário on-line, tendo como referencial teórico e metodológico a perspectiva sócio-retórica dos trabalhos de Swales (1990) e Bazerman (2006a).

Para tanto, inicialmente, delinearemos o quadro teórico em que nos inserimos, a análise sócio-retórica dos gêneros, apresentando conceitos centrais para a consecução do objetivo proposto. Enfocaremos a discussão assentada sobre o deslocamento entre as idéias consideradas "clássicas" (ou pesquisas mais estabilizadas com base em Swales, 1990) e as noções mais recentes fundamentadas em Bazerman (2006a), que, de certa maneira, redefinem (ou reelaboram) os postulados mais estabilizados da vertente sócioretórica americana. Na sequência, abordaremos os aspectos relativos à metodologia da pesquisa. Por fim, apresentaremos a análise empreendida a partir da configuração da organização retórica (SWALES, 1990) e também da análise do sistema de atividades do ombudsman (BAZERMAN, 2006a). 


\section{A NOÇÃO DE GÊNERO: DA AÇÃO RETÓRICA AO SISTEMA DE ATIVIDADES}

A perspectiva “clássica” proposta por Swales $(1990)^{2}$ acerca dos gêneros está enraizada na análise de textos produzidos para fins acadêmicos e profissionais. Ao verificar a falta de clareza no conceito de gênero, o autor buscou uma definição mais "refinada", a partir da noção de gêneros oriunda de quatro áreas distintas: estudos folclóricos, literários, linguísticos e retóricos. Entre os pontos comuns encontrados na maneira como cada área concebe o gênero, pode-se destacar:

a) a descrença em relação à classificação dos gêneros e ao caráter prescritivo de sua definição;

b) a percepção de que os gêneros são importantes para a integração entre passado e presente;

c) o reconhecimento de que os gêneros estão situados no âmbito de comunidades discursivas onde as crenças e práticas dos membros da comunidade são relevantes;

d) a ênfase no propósito comunicativo e na ação social (aqui Swales nos remete a Miller, 1984), que reforçam o conceito de gênero como um meio de ação social situado num contexto sócio-retórico mais amplo; assim sendo, o gênero funciona como um meio para a realização e identificação dos propósitos comunicativos;

e) o interesse em uma estrutura genérica;

f) a compreensão da dupla capacidade gerativa dos gêneros: estabelecer objetivos retóricos e incentivar sua realização.

A noção de gênero para Swales (1990, p. 33) não se vincula apenas à literatura, pois se refere a qualquer categoria distintiva de discurso, seja ele falado ou escrito, com ou sem intenções literárias. $\mathrm{O}$ autor apresenta cinco características centrais na concepção de gênero:

1 - Um gênero é uma classe de eventos comunicativos: o evento comunicativo compreende não somente o discurso e seus participantes, mas também o papel desse discurso e o ambiente/contexto de produção e recepção, incluindo associações históricas e culturais.

2 - O critério principal que transforma um grupo de eventos comunicativos em um gênero é a existência de um conjunto partilhado de propósitos comunicativos: na definição de 1990, o autor sustenta a posição de que a identificação do propósito comunicativo do gênero é o critério de maior importância, já que é o propósito que motiva uma ação .

\footnotetext{
${ }^{2}$ O texto de Swales (1990) foi consultado no original em inglês e as citações aqui apresentadas foram traduzidas pelas autoras para exposição neste artigo.

${ }^{3}$ A identificação do propósito torna-se um ponto problemático e Swales retoma essa questão em trabalho posterior.
} 
3 - Exemplares ou instâncias de gêneros variam em sua prototipicidade: além do propósito comunicativo, outras propriedades, como forma, estrutura e audiência operam para definir um exemplar como prototípico.

4 - A razão ou lógica subjacente a um gênero estabelece restrições em termos de conteúdo, posicionamento e forma: o gênero serve a um propósito que a comunidade discursiva reconhece, e, em razão desse propósito, existem convenções; são elas que estabelecem as restrições em relação ao conteúdo, posicionamento e forma.

5 - A nomenclatura utilizada para os gêneros por uma comunidade discursiva é uma importante fonte de instrução: os participantes mais experientes e ativos das comunidades discursivas nomeiam os gêneros e classes de eventos comunicativos que possuem formas retóricas recorrentes. (SWALES, 1990).

Após a apresentação e definição das características acima apresentadas, Swales propõe a seguinte definição de gênero:

Um gênero compreende uma classe de eventos comunicativos, cujos membros compartilham os mesmos propósitos comunicativos. Tais propósitos são reconhecidos pelos membros mais experientes da comunidade discursiva de origem e constituem a razão do gênero. Essa razão molda a estrutura esquemática do discurso, influencia e restringe as escolhas de conteúdo e estilo. $\mathrm{O}$ propósito comunicativo é um critério privilegiado que opera para manter o escopo do gênero enfocado em determinada ação retórica compatível com o gênero. Além do propósito, exemplares de um gênero exibem vários padrões semelhantes considerando a estrutura, o estilo, o conteúdo e o público alvo. Se todas as expectativas forem realizadas em relação àquilo que é provável para o gênero, a comunidade discursiva original tomará o exemplar como um protótipo. Os nomes dos gêneros são herdados e produzidos pelas comunidades discursivas e importados por outras comunidades, eles constituem uma comunicação etnográfica valiosa, porém necessitam validação. (SWALES, 1990, p. 58).

A definição proposta pelo autor demonstra uma visão integrada de gênero, incluindo os participantes da comunidade discursiva, os eventos comunicativos e as convenções sócio-culturais. Swales (1990) enfatiza o propósito comunicativo como critério privilegiado e central para a análise do gênero; assim, qualquer alteração do propósito comunicativo implica a alteração do gênero, pois é ele que sustenta o gênero, determina sua estrutura esquemática e as escolhas no que se refere ao conteúdo e estilo.

Em 2001, em um artigo publicado em co-autoria com Inger Askehave, Swales aponta algumas fragilidades do conceito. Os autores observam que o propósito comunicativo não é menos visível do que a forma, e, portanto, dificilmente servirá como critério básico para a conceituação de um gênero. (HEMAIS; BIASI-RODRIGUES, 2005, p. 118).

A partir dessas fragilidades encontradas, os autores reelaboram o conceito de propósito comunicativo. Sobre essa reelaboração, Hemais e Biasi-Rodrigues escrevem, 
[...]Askehave \& Swales propõem então abandonar a noção de propósito comunicativo como meio imediato para a classificação de gêneros. No entanto, o analista deve manter em mente que o propósito está em função do resultado da análise, ou seja, descobre-se o propósito pela análise do gênero. E no final das contas, os autores [Askehave e Swales] concluem que o propósito comunicativo seja mantido, não como predominante ou evidente, mas como um critério privilegiado, em função do resultado das investigações sobre o gênero. (HEMAIS; BIASI-RODRIGUES, 2005, p. 118).

Charles Bazerman também traz importantes contribuições para os estudos sobre gêneros textuais. Seus trabalhos apóiam-se nas teorias dos atos de fala de Searle e Austin. Conforme Bazerman (2006a), a produção, circulação e consumo ordenados de textos constituem a própria organização dos grupos sociais; desse modo, as pessoas criam novas realidades de significação, relações e conhecimento fazendo uso de textos.

De acordo com o autor,

Gêneros não são apenas formas. Gêneros são formas de vida, modos de ser. São frames para a ação social. São ambientes para aprendizagem. São lugares onde o sentido é construído. Os gêneros moldam os pensamentos que formam as comunicações através das quais interagimos. Gêneros são os lugares familiares para onde nos dirigimos para criar ações comunicativas inteligíveis uns com outros e são modelos que utilizamos para explorar o não-familiar. (BAZERMAN, 2006b, p. 23, grifos do autor).

Ainda na perspectiva do autor, os gêneros de uma sociedade fornecem um repertório disponivel de formas, ações e motivos. Essas formas são maneiras de ver quais atos são disponíveis e apropriados ao momento (BAZERMAN, 2007, p. 22). Em sua elaboração teórica, o autor apresenta uma série de conceitos que nos conduzem à compreensão de como os textos organizam atividades e pessoas. São eles: fatos sociais, atos de fala, gêneros, sistemas de gêneros e sistemas de atividades.

Fatos sociais são acontecimentos que os seres humanos acreditam ser verdadeiros. Tais fatos influenciam a maneira como as pessoas definem uma determinada situação. Eles consistem em ações significativas realizadas pela linguagem, ou atos de fala (BAZERMAN, 2006a, p. 22). Nossas atividades e organizações sociais são influenciadas e determinadas por textos que, por sua vez, estão apoiados em textos anteriores. Estes textos criam realidades, ou seja, fatos sociais; e grande parte desses fatos sociais depende dos atos de fala, realizados através de formas textuais típicas e padronizadas, também chamadas de gêneros. Bazerman (2006a) diz que uma maneira eficiente de coordenar nossos atos de fala é agir de forma típica, pois se um enunciado ou texto é bem sucedido em uma determinada ocasião, nossa tendência é agir de maneira parecida em uma ocasião similar.

Seguindo padrões comunicativos com os quais nossos interlocutores estão familiarizados, tornamos o que falamos ou escrevemos mais compreensível e atingimos nossos objetivos mais rapidamente. Essas formas de comunicação padronizadas e reconhecíveis nos contextos comunicativos emergem como gêneros. Ao criarmos 
gêneros, estamos, pois, tipificando as situações nas quais estamos inseridos; a tipificação dá forma e significado às circunstâncias e também direciona os tipos de ação que acontecerão posteriormente. Bazerman (2006a, p. 29-30) define tipificação como um processo de mover-se em direção a formas de enunciados padronizados, que reconhecidamente realizam certas ações em determinadas circunstâncias, e de uma compreensão padronizada de determinadas situações.

Resumindo, os processos de tipificação contribuem para a criação de padrões comunicativos e as formas tipificadas utilizadas na comunicação surgem como gêneros textuais. Quanto à definição de gêneros, Bazerman afirma que:

Podemos chegar a uma compreensão mais profunda de gêneros se os compreendermos como fenômenos de reconhecimento psicossocial que são parte de processos de atividades socialmente organizadas. Gêneros são tão-somente os tipos que as pessoas reconhecem como sendo usados por elas próprias e pelo outros. Gêneros são o que nós acreditamos que eles sejam. Isto é, são fatos sociais sobre os tipos de atos de fala que as pessoas podem realizar e sobre os modos como elas os realizam. Gêneros emergem nos processos sociais em que pessoas tentam compreender umas às outras suficientemente bem para coordenar atividades e compartilhar significados com vistas a seus propósitos práticos. (BAZERMAN, 2006a, p. 31, grifos do autor).

Nessa perspectiva, os gêneros tipificam não apenas a forma textual, mas atuam como um modo como as pessoas dão forma às atividades sociais. Para caracterizar como os gêneros se configuram e se enquadram em organizações, papéis e atividades, Bazerman (2006a) propõe os conceitos de conjunto de gêneros, sistema de gêneros e sistema de atividades.

Compreende-se por conjunto de gêneros a coleção de tipos de textos que uma pessoa, num determinado papel, tende a produzir. Já um sistema de gêneros, por sua vez, compreende os vários conjuntos de gêneros utilizados por pessoas que realizam atividades conjuntamente e de uma forma organizada; compreende também as relações padronizadas que se estabelecem na produção, circulação e uso de documentos. $\mathrm{O}$ sistema de gêneros aponta para sequências regulares com que um dado gênero segue um outro gênero, dentro de um fluxo comunicativo típico de um grupo de pessoas.

Considerando a noção de sistema de gêneros proposta por Bazerman, podemos afirmar que:

a) os gêneros encontram-se inter-relacionados uns aos outros em determinados contextos;

b) a noção de sistemas de gêneros amplia a de conjunto de gêneros;

c) o conjunto de gêneros representa somente uma parte dentro de um fluxo comunicativo típico de um grupo de pessoas;

d) o sistema de gêneros é o conjunto completo de gêneros.

O sistema de gêneros, conforme definido anteriormente, é parte de um sistema de atividades. A noção de sistema de atividades aponta para o fato de que, ao definir o sistema de gêneros em que as pessoas estão envolvidas, um indivíduo também identifica 
um frame que organiza seu trabalho, sua atenção e suas realizações. Nessa perspectiva, considerar o sistema de atividades juntamente com o sistema de gêneros é focalizar o que as pessoas fazem discursivamente e como os textos auxiliam as pessoas a fazê-lo.

\section{ASPECTOS METODOLÓGICOS}

Como indicado na introdução do texto, esta pesquisa insere-se nos estudos analíticos de gêneros textuais na perspectiva teórica e metodológica da sócio-retórica, proposta por Swales (1990 e Bazerman (2006a; 2006b; 2007). Os dados da pesquisa constituem-se de quinze exemplares do gênero ombudsman, publicados em três jornais diários on-line, Folha on-line (São Paulo - SP); JMNews (Ponta Grossa - PR); e O Povo (Fortaleza-CE), no período de 07 de dezembro de 2008 a 04 de janeiro de 2009.

Para análise dos dados, partimos de Swales (1990; 1998), cuja proposta se assenta na ideia de que o texto é o ponto de partida para a identificação das intenções, situação e contexto. Nessa perspectiva, Swales (1990, p. 141) apresenta o modelo de análise CARS - Create a Research Space-, baseado em movimentos e passos identificados em introduções de artigos de pesquisa.

Desse modo, na presente pesquisa, desenvolvemos a análise dos movimentos retóricos e do sistema de gêneros do gênero ombudsman. Para análise dos movimentos retóricos, recorremos a dois conceitos-chaves: os movimentos (grandes propósitos que coincidem com as partes estruturais do gênero) e os passos (subpropósitos com os quais os movimentos são construídos). O conjunto de movimentos e passos constitui os blocos textuais de informações que caracterizam a estrutura interna de um determinado gênero, neste caso, o ombudsman.

Para análise do sistema de gêneros a partir da proposta de Bazerman (2006a), adotamos como parâmetros analíticos os conceitos de conjunto de gêneros, sistemas de gêneros e sistema de atividades. Examinar o conjunto de gêneros nos possibilitou observar a extensão e a variedade do trabalho escrito requerido por um determinado papel social e identificar o conhecimento de gênero e as habilidades de escrita necessárias para alguém, em nosso caso, os jornalistas que desempenham a função de Ombudsman, realizar este trabalho. Analisar o sistema de gêneros permitiu-nos compreender as interações práticas, funcionais e sequenciais de documentos. Através dessa compreensão é que foi possível verificar como o Ombudsman, ao escrever uma nova coluna, está intertextualmente situado dentro de um sistema. Nesse contexto, sua escrita é direcionada pelas expectativas de gêneros e amparada por recursos sistêmicos. Finalmente, em nossa pesquisa, o sistema de atividades nos possibilitou uma compreensão global do trabalho do jornalista realizado pelo sistema, além de evidenciar o modo como cada texto escrito contribui para o trabalho final do Ombudsman ${ }^{4}$.

\footnotetext{
${ }^{4}$ Vale salientar, conforme apresentado anteriormente, que Bazerman também desenvolve conceitos como fatos sociais e atos de fala. Contudo, tais conceitos não foram contemplados em nossa análise, pois uma análise dos dados segundo esses conceitos extrapola o objetivo desta pesquisa.
} 
Até o momento, apresentamos os conceitos teóricos que sustentam epistemologicamente nosso trabalho, bem como o percurso metodológico da pesquisa. A seguir, apresentaremos a análise empreendida do gênero ombusdman.

\section{A ORGANIZAÇÃO RETÓRICA DO GÊNERO}

$\mathrm{Na}$ análise da organização retórica do gênero ombudsman, foram detectados cinco movimentos retóricos, que são:
a) situar o leitor;
b) introduzir o tema;
c) apresentar a crítica ao jornal;
d) concluir a crítica;
e) apresentar credenciais.

Esses movimentos, por sua vez, são subdivididos em 13 passos (sub-ação retórica), conforme podemos observar no Quadro 1, onde apresentamos a organização retórica do gênero ombudsman com base na concepção de Swales (Modelo CARS, 1990).

QUADRO1. Organização retórica do gênero ombudsman.

\begin{tabular}{|c|c|}
\hline $\begin{array}{l}\text { MOVIMENTOS } \\
\text { Ação retórica }\end{array}$ & $\begin{array}{c}\text { PASSOS } \\
\text { Sub-ação retórica }\end{array}$ \\
\hline I. Situar o leitor & $\begin{array}{l}\text { 1. Marcar autoria } \\
\text { 2. Estabelecer o título } \\
\text { 3. Estabelecer o subtítulo, que antecipa o tema }\end{array}$ \\
\hline II. Introduzir o tema & $\begin{array}{l}\text { 1. Introduzir o tema } \\
\text { 2. Apresentar a opinião do leitor }\end{array}$ \\
\hline III. Apresentar a crítica ao jornal & $\begin{array}{l}\text { 1. Criticar e defender o jornal } \\
\text { 2. Inserir exemplos } \\
\text { 3. Apresentar ideias sínteses } \\
\text { 4. Reafirmar posicionamentos }\end{array}$ \\
\hline IV. Concluir a crítica & 1. Apresentar sugestões para o jornal \\
\hline V. Apresentar credenciais & $\begin{array}{l}\text { 1. Indicar a próxima coluna } \\
\text { 2. Apresentar credencial do Ombudsman (autor) } \\
\text { 3. Disponibilizar informações para o contato com } \\
\text { o Ombudsman }\end{array}$ \\
\hline
\end{tabular}


No quadro 2, explicitamos os movimentos mencionados anteriormente, a partir da organização retórica de um exemplar do gênero, que foi publicado no Jornal Folha de S. Paulo ${ }^{5}$.

QUADRO 2. Organização retórica de um exemplar de ombudsman publicado na Folha on-line (2008).

\begin{tabular}{|c|c|c|}
\hline MOVIMENTOS & PASSOS & COMPONENTES TEXTUAIS \\
\hline \multirow[b]{3}{*}{$\begin{array}{l}\text { Movimento I } \\
\text { Situar o leitor }\end{array}$} & $\begin{array}{l}\text { 1. Marcas de } \\
\text { autoria }\end{array}$ & 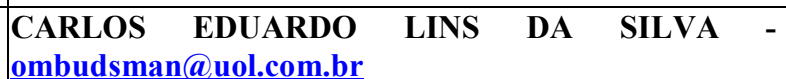 \\
\hline & 2. Título & Quando é preciso chocar sem morbidez \\
\hline & $\begin{array}{l}\text { 3. Subtítulo que } \\
\text { antecipa o tema }\end{array}$ & $\begin{array}{l}\text { Fotografias chocantes podem ajudar a manter vivos na } \\
\text { memória coletiva horrores inomináveis e, com isso, } \\
\text { dificultar a ocorrência de similares }\end{array}$ \\
\hline \multirow{2}{*}{$\begin{array}{l}\text { Movimento II } \\
\text { Estabelecer o } \\
\text { tema }\end{array}$} & $\begin{array}{c}\text { 1. Introduzir o } \\
\text { tema }\end{array}$ & $\begin{array}{l}\text { DESDE O CASO da morte de Isabella Nardoni, em } \\
\text { abril, o ombudsman não recebia tantas mensagens sobre } \\
\text { um mesmo assunto numa semana, como nesta, de Ano- } \\
\text { Novo, sobre o conflito entre Israel e palestinos. Como é } \\
\text { natural, com grande carga de emoção em todas e clara } \\
\text { divisão entre as que veem no jornal proteção para um ou } \\
\text { outro lado. }\end{array}$ \\
\hline & $\begin{array}{l}\text { 2. Apresentar a } \\
\text { opinião do leitor }\end{array}$ & $\begin{array}{l}\text { Dois leitores se queixaram de fotos de crianças mortas. } \\
\text { Zuleika Haddad perguntou: "Por que a Folha precisa } \\
\text { estampar foto de uma menina de } 4 \text { anos em seu } \\
\text { funeral?". Geraldo Pietragalla Filho argumentou que as } \\
\text { fotos "em nada contribuem para a compreensão dessa } \\
\text { guerra insana; são manifestações mórbidas". }\end{array}$ \\
\hline \multirow{3}{*}{$\begin{array}{l}\text { Movimento III } \\
\text { Apresentar a } \\
\text { crítica ao jornal }\end{array}$} & $\begin{array}{c}\text { 1. Crítica e } \\
\text { defesa do jornal }\end{array}$ & $\begin{array}{l}\text { A morbidez deve ser evitada a todo custo, e o jornal } \\
\text { precisa tomar muito cuidado com isso. Não acho que } \\
\text { tenha esbarrado nela por enquanto. } \\
\text { Imagens fotográficas chocantes podem servir a } \\
\text { propósitos humanitários e ajudar a manter vivos na } \\
\text { memória coletiva horrores inomináveis e, com isso, } \\
\text { dificultar a ocorrência de similares. }\end{array}$ \\
\hline & $\begin{array}{l}\text { 2. Utilização de } \\
\text { exemplos }\end{array}$ & $\begin{array}{l}\text { Como as dos prisioneiros dos campos de concentração de } \\
\text { Auschwitz e Dachau, das deformidades provocadas em } \\
\text { crianças pela poluição na baía de Minamata, das torturas } \\
\text { impostas a prisioneiros iraquianos por soldados dos EUA } \\
\text { em Abu Ghraib, dos efeitos de bombas de napalm sobre } \\
\text { civis sul-vietnamitas, como a garota Kim Phuc, na foto } \\
\text { acima, feita por Nick Ut, em } 1972 \text {. }\end{array}$ \\
\hline & $\begin{array}{l}\text { 3. Apresentar } \\
\text { idéias sínteses }\end{array}$ & $\begin{array}{l}\text { Não é agradável ver essas cenas. Mas às vezes é } \\
\text { indispensável. } \\
\text { Quanto à cobertura em palavras do que vem ocorrendo } \\
\text { em Gaza, a Folha começou muito mal. No sábado, } \\
\text { enquanto os primeiros ataques aéreos ocorriam e } \\
\text { prenunciavam o que viria, o jornal circulava com a } \\
\text { avaliação de que a expectativa era a de que as tensões } \\
\text { arrefecessem depois de Israel ter permitido a chegada de } \\
\text { medicamentos e alimentos a Gaza. } \\
\text { Foi o contrário que ocorreu. Nunca é bom para um jornal } \\
\text { antecipar algo e ocorrer o oposto. Mas faz parte dos } \\
\text { riscos desta atividade. }\end{array}$ \\
\hline
\end{tabular}

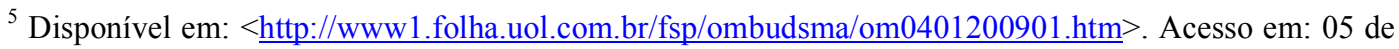
jan. de 2009. 


\begin{tabular}{|c|c|c|}
\hline & $\begin{array}{l}\text { 4. Reafirmação } \\
\text { de } \\
\text { posicionamento } \\
\text { em relação ao } \\
\text { jornal }\end{array}$ & $\begin{array}{l}\text { O importante é que a Folha entendeu logo a importância } \\
\text { dos fatos e melhorou muito ao longo da semana no seu } \\
\text { acompanhamento. Na segunda, já estava na fronteira de } \\
\text { Israel com Gaza seu enviado especial, que tem oferecido } \\
\text { ao leitor o que só um jornalista do próprio veículo } \\
\text { consegue fazer: mostrar os acontecimentos da } \\
\text { perspectiva de real interesse do público específico. } \\
\text { A preocupação com o equilíbrio tem sido ostensiva. } \\
\text { Sempre saem artigos em defesa dos dois lados em espaço } \\
\text { comparável, descrevem-se as condições de vida dos } \\
\text { habitantes das duas áreas (apesar da proibição à entrada } \\
\text { de jornalistas estrangeiros em Gaza), o texto de Adrian } \\
\text { Hamilton, do "Independent", na sexta, sobre as causas do } \\
\text { conflito, é exemplarmente isento. }\end{array}$ \\
\hline $\begin{array}{l}\text { Movimento IV } \\
\text { Concluir a } \\
\text { crítica }\end{array}$ & $\begin{array}{c}\text { 1. Sugestões para } \\
\text { o jornal }\end{array}$ & $\begin{array}{l}\text { Ainda falta muito a fazer, inclusive analisar com mais } \\
\text { profundidade as posições do governo brasileiro e suas } \\
\text { pretensões. Não será possível agradar a todos os leitores. } \\
\text { Mas o caminho que o jornal vem seguindo é o certo. }\end{array}$ \\
\hline \multirow{3}{*}{$\begin{array}{l}\text { Movimento V } \\
\text { Apresentar } \\
\text { credenciais }\end{array}$} & $\begin{array}{c}\text { 1. Indicação } \\
\text { da próxima } \\
\text { coluna }\end{array}$ & $\begin{array}{l}\begin{array}{l}\text { Próximo Texto: } \\
\text { diferenças }\end{array} \\
\underline{\underline{\text { Indice }}}\end{array}$ \\
\hline & $\begin{array}{l}\text { 2. Credencial do } \\
\text { Ombudsman } \\
\text { (autor) }\end{array}$ & $\begin{array}{l}\text { Carlos Eduardo Lins da Silva é o Ombudsman da } \\
\text { Folha desde } 24 \text { de abril de } 2008 \text {. O Ombudsman tem } \\
\text { mandato de um ano, renovável por mais dois. Não pode } \\
\text { ser demitido durante o exercício da função e tem } \\
\text { estabilidade por seis meses após deixá-la. Suas } \\
\text { atribuições são criticar o jornal sob a perspectiva dos } \\
\text { leitores, recebendo e verificando suas reclamações, e } \\
\text { comentar, aos domingos, o noticiário dos meios de } \\
\text { comunicação. }\end{array}$ \\
\hline & $\begin{array}{l}\text { 3. Informações } \\
\text { para o contato } \\
\text { com o } \\
\text { Ombudsman }\end{array}$ & $\begin{array}{l}\text { Cartas: al. Barão de Limeira } 425,8^{\circ} \\
\text { andar, São Paulo, SP CEP 01202-900, } \\
\text { a/c Carlos Eduardo Lins da } \\
\text { Silva/ombudsman, ou pelo fax }(011) \\
\text { 3224-3895. } \\
\text { Endereço eletrônico: } \\
\text { ombudsman@uol.com.br. } \\
\text { Contatos telefônicos: ligue } 0800 \\
\text { 0159000; se deixar recado na secretária } \\
\text { eletrônica, informe telefone de contato } \\
\text { no horário de atendimento, entre } 14 \mathrm{~h} \text { e } \\
\text { 18h, de segunda a sexta-feira. }\end{array}$ \\
\hline
\end{tabular}

Conforme dito anteriormente, a análise evidenciou cinco movimentos retóricos:

1. Situar o leitor - Esse movimento objetiva apresentar ao leitor as informações concernentes aos seguintes aspectos: autoria; título do texto e subtítulo que, não raras vezes, constitui-se de um recorte de uma 'fala' do Ombudsman do "corpo" do texto ${ }^{6}$. Assim, trata-se de elementos que permitem ao leitor o reconhecimento prévio do tema a ser tratado pelo Ombudsman.

\footnotetext{
${ }^{6} \mathrm{O}$ procedimento de enquadrar uma porção textual em espaço destacado do texto é chamado, no campo do trabalho jornalístico, de "olho" ou "janela".
} 
2. Estabelecer o tema - Nesse movimento, é introduzida, de fato, a temática a ser discutida pelo Ombudsman. Além disso, é também apresentada a opinião do leitor, que é o motivador da crítica, uma vez que o Ombudsman é o "representante" desse leitor-participante.

3. Apresentar a crítica ao jornal - Esse movimento constitui-se na parte mais densa do gênero, pois é nele que estão alocados os elementos centrais do gênero, como: manifestações explícitas de críticas ao jornal; movimentos de defesa (parcial) do jornal; apresentação de ideias síntese e a reafirmação de posicionamento do Ombudsman em relação ao jornal.

4. Concluir a crítica ao jornal - Nesse movimento, o Ombudsman apresenta sugestões de melhoria ao jornal, para que os problemas apontados pelos leitores sejam sanados.

5. Apresentar credenciais - Esse movimento se caracteriza como uma espécie de pé-biográfico; é o espaço onde o Ombudsman é apresentado (autor), explicitando o papel dele como "ouvidor"; assim, apresenta-se um resumo da função desenvolvida por ele. Além disso, esse movimento final é responsável por apresentar as possibilidades para o leitor entrar em contato com o jornalista e, desse modo, manifestar críticas ao jornal.

Nesta seção, expusemos a análise da organização retórica do gênero. Na próxima seção, apresentaremos a análise relativa ao sistema de atividades do gênero ombudsman.

\section{O SISTEMA DE ATIVIDADES DO GÊNERO OMBUDSMAN}

O gênero ombudsman está intimamente ligado a uma prática discursiva sóciohistoricamente situada; à instauração de uma ação retórica; e a um agir no mundo por meio do discurso. Isso se relaciona à perspectiva do gênero como ação social e como uma atividade.

Segundo Bazerman (2006a), em áreas em que o produto principal é produzir e distribuir símbolos, como é o caso do jornalismo, o sistema de atividades é organizado de forma central em torno de documentos escritos. Nesse sentido, o autor enfatiza que considerar o sistema de atividades em conjunto com o sistema de gêneros constitui-se em focalizar os que as pessoas fazem e como os textos ajudam as pessoas a fazê-lo, em vez de focalizar os textos em si mesmos. (BAZERMAN, 2006a, p. 34).

Desse modo, podemos dizer que o jornalista que ocupa o cargo de Ombudsman de um jornal mobiliza um conjunto complexo de ações que se realizam pela (e na) linguagem, interligadas a um conjunto de gêneros que integram o sistema de atividades do gênero ombudsman no campo do jornalismo.

Para a compreensão desse gênero, que se realiza no campo do trabalho jornalístico, bem como, para compreender o sistema de atividades imbricado na produção do mesmo, partimos das seguintes questões norteadoras: Quais são os sujeitos que interagem na produção desse gênero? Que gêneros são mobilizados pelos sujeitos para executar seu papel no sistema de atividades do gênero? Quais são as ações mobilizadas pelos sujeitos no sistema de atividades do gênero? 
De acordo com Mendes (1999), o Ombudsman tem três funções: ouvir os leitores, escrever um boletim diário criticando o jornal ${ }^{7}$ (que circula internamente entre os jornalistas da publicação) e preparar uma coluna semanal para ser publicada. Tais funções podem ser relacionadas ao sistema de atividades do gênero ombudsman.

As funções exercidas pelo Ombudsman no sistema de atividades do gênero ombudsman se realizam por meio de textos que circulam no campo do trabalho do jornalismo e têm como principal ação de linguagem fazer a crítica ao jornal. A reunião de gêneros mobilizados pelo jornalista (Ombudsman) indica o conjunto de gêneros textuais que esse sujeito pode e/ou deve utilizar para desempenhar seu papel na rede de atividades, papel este imprescindível para que a atividade do gênero ombudsman possa se efetivar, ou seja, para que a crítica ao jornal seja realizada.

No quadro a seguir, sistematizamos os conjuntos de gêneros e as respectivas atividades relacionadas aos sujeitos envolvidos no sistema de atividades do referido gênero.

QUADRO 3. Conjunto de gêneros mobilizados na produção do gênero ombudsman.

\begin{tabular}{|l|c|l|}
\hline \multicolumn{1}{|c|}{ Sujeitos envolvidos } & Conjunto de gêneros & \multicolumn{1}{|c|}{ Atividade desempenhada } \\
\hline \multirow{3}{*}{ Leitor-participante } & $\begin{array}{l}\text { E-mail } \\
\text { Carta } \\
\text { Telefonema }\end{array}$ & $\begin{array}{l}\text { Expressar a sua crítica em } \\
\text { relação ao jornal. }\end{array}$ \\
\hline \multirow{3}{*}{ Jornalista (Ombudsman) } & $\begin{array}{l}\text { E-mail } \\
\text { Carta } \\
\text { Telefonema }\end{array}$ & $\begin{array}{l}\text { Leitura e escuta das } \\
\text { manifestações/críticas dos } \\
\text { leitores. }\end{array}$ \\
\cline { 2 - 3 } & Artigo assinado & $\begin{array}{l}\text { Leitura dos textos publicados } \\
\text { pelo jornal para serem cotejados } \\
\text { com as manifestações dos } \\
\text { deitores. }\end{array}$ \\
\cline { 2 - 3 } & Comentário & $\begin{array}{l}\text { Anotações diversas para a escrita } \\
\text { do ombudsman e escrita do texto } \\
\text { final. }\end{array}$ \\
\hline
\end{tabular}

Tendo como fundamento a proposta de conjunto de gêneros e sistema de atividades de Bazerman (2006), analisamos as atividades desenvolvidas pelos sujeitos no campo do trabalho do jornalismo e que estão imbricadas na produção do gênero ombudsman.

Nesse sentido, os sujeitos que se constituem em interactantes no sistema de atividades do gênero ombudsman são: o leitor-participante, o jornalista que ocupa o cargo de Ombudsman no jornal e os demais profissionais (jornalistas) da redação do jornal.

Ao leitor-participante cabe a incumbência de manifestar sua crítica ao jornalista. Para isso, utiliza-se de cartas, e-mails e telefonemas. Segundo Silva (2009), no que se refere ao contato feito pelo leitor, cerca de $90 \%$ das vezes esse é feito por e-mail; cerca de $7 \%$ a $8 \%$ são telefonemas e o restante são cartas físicas.

\footnotetext{
${ }^{7}$ Vale salientar que essa função do Ombudsman, "escrever um boletim contendo críticas ao jornal para circulação interna", é um dado apresentado por Mendes (1999). Contudo, em entrevista, via e-mail, com o Ombudsman da Folha on-line de São Paulo, observamos uma prática diferenciada. Segundo Silva (2009), o Ombudsman da Folha on-line, no processo de elaboração do ombudsman, assume duas funções: ouvir os leitores e escrever a coluna semanal.

${ }^{8}$ Os leitores têm a possibilidade de deixar mensagens gravadas, via telefone, que serão escutadas pelo Ombudsman posteriormente. Não se trata de uma conversa via telefone.
} 
Ao jornalista que ocupa a função de Ombudsman cabe a responsabilidade de: a) receber as manifestações/críticas dos leitores; b) analisá-las; e c) escrever o ombudsman semanalmente. Silva (2009) descreve a segunda etapa da atividade (análise das manifestações dos leitores) da seguinte maneira: faz-se um balanço que leve em conta: o número de manifestações sobre o assunto; a urgência do tema; a distribuição temática; e o nível de conhecimento do jornalista sobre o assunto. Na etapa final é que ocorre a escrita propriamente dita da coluna do ombudsman. O jornalista diz que, apesar de ser publicado somente aos domingos, o texto é escrito na sexta-feira, sendo que o tema é definido na quarta ou quinta-feira da semana anterior à da publicação da coluna.

O gênero ombudsman pode ser considerado um sistema de gênero, haja vista que visando à sua produção e circulação são mobilizadas diversas ações (atividades) que requerem a utilização de outros gêneros para que se efetive a atividade central desse gênero, que é manifestar a crítica ao jornal. Desse modo, o autor jornalista/Ombudsman - lança mão de diversos textos, de diversos gêneros, que se interrelacionam para alcançar uma finalidade: manifestar (representar) a opinião do leitor, fazendo a crítica ao jornal e constituindo-se com o "porta-voz" do leitor do jornal.

O gênero não pode ser produzido sem que haja a mobilização de outros gêneros e que os demais interactantes desempenhem sua função nos sistema, o que evidencia uma relação de interdependência entre os sujeitos que participam desse sistema de atividades.

A atividade desempenhada pelos sujeitos não pode ser analisada isoladamente, uma vez que há uma ligação com os demais gêneros do jornal. Assim, a seguir, apresentamos o sistema de atividades do gênero ombudsman, evidenciando os passos típicos constitutivos para se chegar à produção do gênero:

1. Leitor-participante - envia as manifestações de crítica através de e-mails, telefonemas, cartas.

2. Ombudsman - recebe as manifestações dos leitores através de e-mails, telefonemas, cartas.

3. Ombudsman - analisa as manifestações dos leitores; faz anotações, comentários.

4. Ombudsman - delimita o tema da coluna a partir de suas anotações.

5. Ombudsman - escreve o texto (inscrito no gênero ombudsman), que posteriormente será publicado pela empresa jornalística.

A partir desse encadeamento de ações, podemos observar que, no gênero ombudsman, a interação entre leitor-participante e jornalista/Ombudsman (e também as ações de linguagem por eles mobilizadas) é fundamental para que o objetivo discursivo do gênero se concretize.

\section{CONSIDERAÇÕES FINAIS}

Neste artigo, objetivamos empreender uma análise do gênero ombudsman, tendo como aporte teórico e metodológico a linha sócio-retórica para estudo de gêneros. A escolha 
do gênero se deu em virtude da singularidade do ombudsman no que se refere à mobilização de ações de linguagem para a realização de sua finalidade interacional. Longe de termos a pretensão de aprofundar questões epistemológicas, a finalidade foi contribuir no processo de contextualização de atividades típicas do trabalho da esfera do jornalismo.

Assim, com relação à análise aqui apresentada, o gênero em questão apresenta em sua organização retórica cinco movimentos retóricos, que são: a) situar o leitor; b) introduzir o tema; c) apresentar a crítica ao jornal; d) concluir a crítica: e) apresentar credenciais. Esses movimentos, por sua vez, são subdivididos em 13 passos (sub-ação retórica). Com relação ao sistema de atividades do gênero, destacamos que com vistas à produção e circulação desse gênero são mobilizadas diversas ações (atividades) que requerem a utilização de outros gêneros para que se efetive a atividade central desse gênero, que é manifestar a crítica ao jornal. Nesse sistema de atividades, destaca-se o papel do autor-jornalista, que lança mão de diversos textos para produzir o ombudsman, e também o papel do leitor-participante, que envia suas mensagens/críticas ao jornal, e, sendo assim, também atua como um agente na ação de linguagem empreendida para a produção e circulação do gênero. Isso aponta para a complexidade da constituição desse gênero na esfera do trabalho do jornalismo.

\section{REFERÊNCIAS}

BHATIA, V. K. Analysing genre: Language use in professional settings. London: Longman, 1993.

BAZERMAN, C. Shaping written knowledge: The genre and activity of the experimental article in science. Madison, WI: University of Wisconsin Press, 1988.

BAZERMAN, C; A. P. DIONÍSIO; J. C. HOFFNAGEL. (Orgs.). Gêneros textuais, tipificação e interação. 2. ed. Tradução e organização de Ângela Paiva Dionísio e Judith Chambliss Hoffnagel. São Paulo: Cortez, 2006a.

. Gêneros, agência e escrita. Tradução e organização de Ângela Paiva Dionísio e Judith

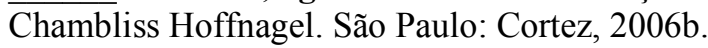

. Escrita, gênero e interação social. Tradução e organização de Ângela Paiva Dionísio e Judith Chambliss Hoffnagel. São Paulo: Cortez, 2007.

CRISTÓVÃO, V. L. L.; NASCIMENTO, E. L. (Orgs.). Gêneros textuais: Teoria e Prática. Londrina: Moriá, 2004.

FREEDMAN, A. (Org.) Learning and teaching genre. Portsmouth: Boynton, Cook Publishers, 1994.

HEIMAS, B. \& BIASI-RODRIGUES, B. A Proposta Sócio-retórica de John Swales para o estudo dos gêneros textuais. In: In: MEURER, J.L.; BONINI, A.; MOTTA-ROTH, D. (orgs.). Gêneros: teorias, métodos e debates. São Paulo: Parábola Editorial, 2005. p. 108-129.

MILLER, C. Genre as a Social Action. In: FREEDMAN, A; MEDWAY, P. (orgs.) Genre and the new rhetoric. London: Taylor \& Francis. 1984. p. 23-42. 
SWALES, J. M. Genre analysis: English in Academic and Research Settings. Cambridge: CUP, 1990.

Other floors, other voices: a textography of a small university building. Mahwah, NJ: Lawrence Erlbaum, 1998.

SILVA, Carlos Eduardo Lins da. O trabalho do ombudsman. Entrevista concedida via e-mail em 10 de março de 2009/30 de abril de 2009.

MENDES, Jairo Faria. Ombudsman: o espaço para a autocrítica nos jornais. Instituto

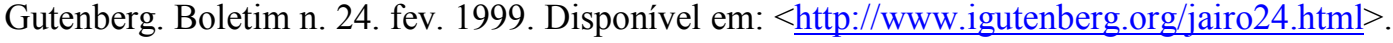
Acesso em: 20 de mar. 2009.

MINUZZI, M. V. Leitor no mecanismo do ombudsman de imprensa - heterogeneidades e idealizações. UNIrevista. São Leopoldo. vol. 1, $\mathrm{n}^{\circ} 3$ : jul., 2006. p. 11. Disponível em: $<$ http://www.unirevista.unisinos.br/_pdf/UNIrev_Minuzzi.pdf $>$. Acesso em: 21 de mar. 2009.

\section{REFERÊNCIAS DOS DADOS DE PESQUISA}

BUCHOLDZ, A.P. Os balanços de 2008. JM News Online: Ponta Grossa, 30, dez. 2008. Disponível em:

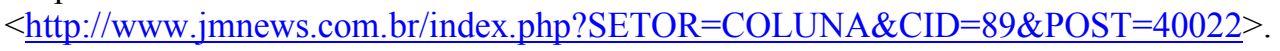
Acesso em: 05 jan 2009.

BUCHOLDZ, A.P. Revisar para não errar. JM News Online: Ponta Grossa, 21, dez. 2008. Disponível em: $<$ http://www.jmnews.com.br/index.php?SETOR=COLUNA\&CID=89\&POST=39282>. Acesso em: 05 jan. 2009.

BUCHOldZ, A. P. Dossiê da Ronda. JM News Online: Ponta Grossa, 07, dez. 2008. Disponível em: $<$ http://www.jmnews.com.br/index.php?SETOR=COLUNA\&CID=89\&POST=36242 $>$. Acesso em: 05 jan. 2009.

SILVA, C. E.L. Quando é preciso chocar sem morbidez. Folha Online: São Paulo, 04, jan. 2009. Disponível em: <http://www1.folha.uol.com.br/fsp/ombudsma/om0401200901.htm>. Acesso em: 05 jan. 2009.

SILVA, C.E.L. Ave Jano! 12 desejos para 2009. Folha Online: São Paulo, 28, dez. 2008. Disponível em: < http://www1.folha.uol.com.br/fsp/ombudsma/om2812200801.htm>. Acesso em: 05 jan. 2009.

SILVA, C.E.L. Jornalismo e Direitos Humanos. Folha Online: São Paulo, 22, dez. 2008. Disponível em: < http://www1.folha.uol.com.br/fsp/ombudsma/om2112200801.htm>. Acesso em: 05 jan. 2009.

SILVA, C.E.L. Aviso. Folha Online: São Paulo, 15 dez. 2008. Disponível em:

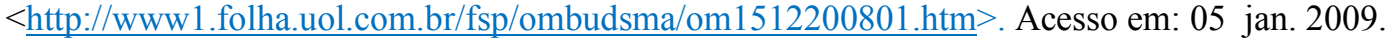


SILVA, C.E.L. Muitas outras águas ainda vão rolar. Folha Online: São Paulo, 14, dez. 2008. Disponível em: < http://www1.folha.uol.com.br/fsp/ombudsma/om1412200801.htm>. Acesso em: 05 jan. 2009.

SILVA, C.E.L. Os dilemas de uma cinquentona. Folha Online: São Paulo, 07, dez. 2008. Disponível em: < http://www1.folha.uol.com.br/fsp/ombudsma/om0712200801.htm>. Acesso em: 05 jan. 2009.

VERLAINE, P. Valeu a pena? O Povo Online: Fortaleza, 03, jan. 2009.

Disponível em: < http://www.opovo.com.br/ombudsman/847643.html $>$. Acesso em: 05 jan. 2009.

VERLAINE, P. Portal. O Povo Online: Fortaleza, 27, dez. 2008. Disponível em: $<$ http://www.opovo.com.br/ombudsman/846609.html $>$. Acesso em: 05 jan. 2009.

VERLAINE, P. 40 anos do AI-5. O Povo Online: Fortaleza, 20, dez. 2008. Disponível em: $<$ http://www.opovo.com.br/ombudsman/845605.html $>$. Acesso em: 05 jan. 2009.

VERLAINE, P. Cid e a crise. O Povo Online: Fortaleza, 13, dez. 2008. Disponível em: $<$ http://www.opovo.com.br/ombudsman/844299.html $>$. Acesso em: 05 jan. 2009.

VERLAINE, P. Crise boa? O Povo Online: Fortaleza, 06, dez. 2008. Disponível em: $<$ http://www.opovo.com.br/ombudsman/842948.html>. Acesso em: 05 jan. 2009. 